\title{
Percutaneous stent implantation to stenotic bioprosthetic valves in the pulmonary position
}

Carlos A. C. Pedra, MD* Henri Justino, MD, FRCPC**

David G. Nykanen, MD, FRCPC

Glen VanArsdell, MD, FRCSC

John G. Coles, MD, FRCSC

William G. Williams, MD, FRCSC

Robert M. Freedom, MD, FRCPC

Lee N. Benson, MD, FRCPC
Background: We evaluated stent implantation across stenotic bioprosthetic pulmonary valves in 9 patients.

Methods: Nine patients (6 male patients) underwent stent implantation across stenotic bioprosthetic pulmonary valves between July 1996 and July 1999 at the Hospital for Sick Children, Toronto. Catheter intervention was indicated if echocardiography revealed Doppler estimates of right ventricular pressure of more than two thirds of systemic arterial pressure (or systolic septal flattening with an estimated gradient of $>60 \mathrm{~mm} \mathrm{Hg}$ across the valve prosthesis). Catheterization was performed during general anesthesia at an age (mean $\pm \mathrm{SD}$ ) of $9.3 \pm 3.5$ years and a weight of $32.0 \pm 17.1 \mathrm{~kg} 5.9 \pm 1.8$ years after surgical insertion of a bioprosthetic valve in the pulmonary position: 7 patients with tetralogy of Fallot, 1 patient with congenital pulmonary stenosis-insufficiency, and 1 patient after a Rastelli operation. All had systolic septal flattening and right ventricular dilatation with moderate-tosevere pulmonary insufficiency before intervention. Fluoroscopy times were $33.1 \pm$ 9.5 minutes. Seven patients received a single P4014 stent, and 2 received single P308 stents (Palmaz; Johnson \& Johnson Interventional Systems, Warren, NJ) without significant complications.

Results: The right ventricular systemic pressure decreased acutely from $83 \% \pm 16 \%$ to $41 \% \pm 10 \%(P<.001, \mathrm{n}=9)$, and the transvalvular gradient decreased from $49.7 \pm 8.5$ to $11.0 \pm 5.9 \mathrm{~mm} \mathrm{Hg}(P<.001, \mathrm{n}=8)$. During the follow-up period $(10.9 \pm 8.1$ months, $\mathrm{n}=8), 1$ patient had an unsuccessful attempt at redilation of the stent (right ventricular pressure, $60 \%$ systemic) and underwent uneventful surgical pulmonary valve replacement. None of the remaining patients had echocardiographic evidence of systolic septal flattening, and right ventricular dimensions did not change significantly.

Conclusion: Stent implantation is a safe and effective means of providing palliative relief of obstructed bioprosthetic valves in the pulmonary position and can safely delay the requirement for pulmonary valve replacement. nese" de Cardiologia, São Paulo, SP, Brasil.

**Current address: Division of Cardiology, Children's Hospital of Eastern Ontario, Ottawa, Ontario, Canada.

J Thorac Cardiovasc Surg 2002;124:82-7

Copyright (C) 2002 by The American Association for Thoracic Surgery

0022-5223/2002 $\$ 35.00+0 \quad \mathbf{1 2 / 1 / 1 2 2 3 0 9}$

doi:10.1067/mtc.2002.122309

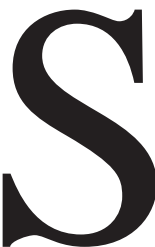

urgical insertion of a bioprosthetic valve to reconstruct the right ventricular (RV) outflow tract has been used in the repair of complex cardiac defects, such as tetralogy of Fallot and transposition of the great arteries with ventricular septal defect and pulmonary stenosis. ${ }^{1-3}$ Although such valves tend to perform reasonably well in the pulmonary position, ${ }^{4}$ late stenosis caused by leaflet calcification and size mismatch as a result of body growth remain universal issues, committing the patient 

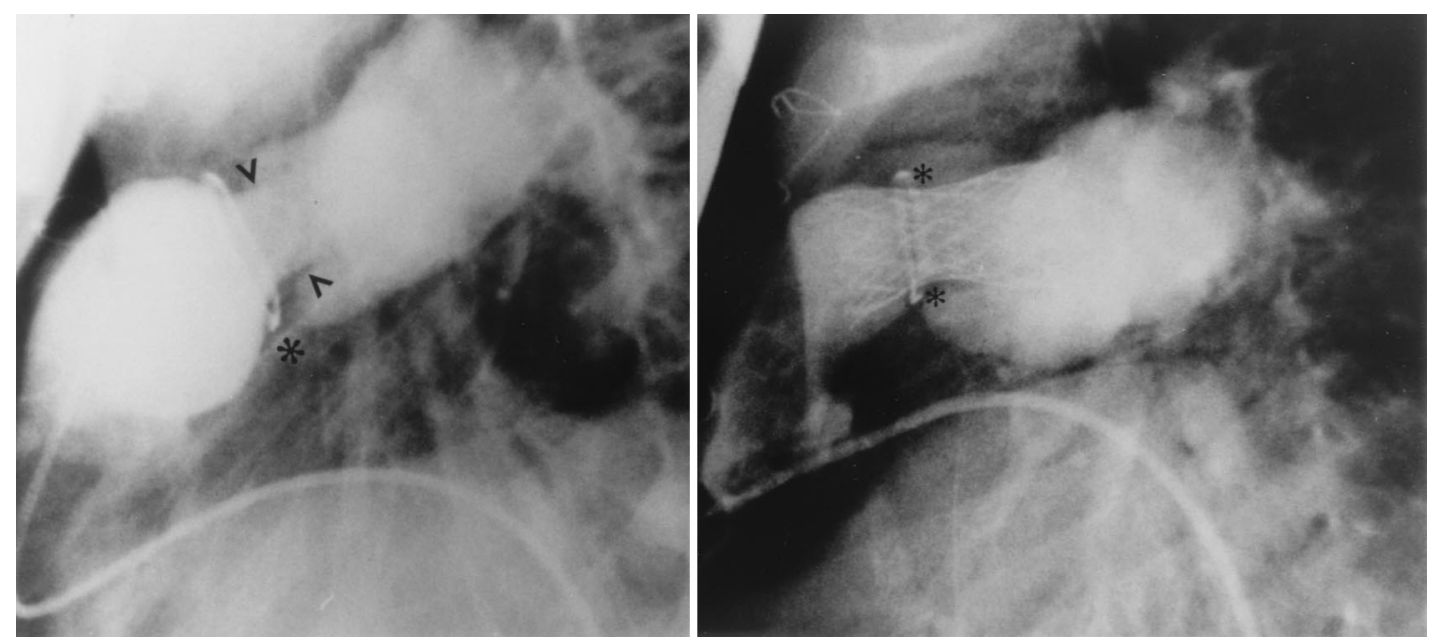

Figure 1. Left panel, Lateral angiogram in the RV outflow tract defining the bioprosthetic valve (*). Valve leaflets (arrows) were thickened and fused in a semiopened position. Right panel, Immediately after stent implantation (same projection as in left panel). Note the slight waist in the stent at the valve region (*) and the distance between the stent and radiopaque sewing ring (usually 3-4 $\mathrm{mm}$ ).

to further procedures..$^{5-7}$ Although surgical valve replacement can be performed at a low mortality risk, ${ }^{3,8}$ morbidity is associated with repeat sternotomy and cardiotomy, and technical difficulties arise from previous operations. Percutaneous balloon valvuloplasty has shown only marginal efficacy for relief of such obstructions. ${ }^{9-14}$ On the other hand, in the setting of RV to pulmonary artery conduits, a significant prolongation of conduit life span has been safely achieved after implantation of balloon expandable intravascular stents. ${ }^{15-18}$ In this study we report our experience with this palliative strategy to relieve obstructions in bioprosthetic valves in the pulmonary position.

\section{Methods}

\section{Study Design}

A computer database search identified 9 patients who underwent placement of intravascular stents across bioprosthetic valves in the pulmonary position between July 1996 and July 1999 at the Hospital for Sick Children, Toronto, Ontario, Canada. Data were compiled retrospectively from the hospital records, including clinic visits, echocardiograms, catheterizations, and surgical notes. In particular, the type of valve, diameter, and position were noted. Informed consent for the procedures was obtained from parents following guidelines of the Human Subject Protection Committee of the Hospital for Sick Children, University of Toronto.

\section{Indications for Intervention}

Patients with an estimated RV systolic pressure exceeding two thirds of systemic arterial pressure or a transvalvular gradient of at least $60 \mathrm{~mm} \mathrm{Hg}$, as documented with Doppler echocardiography (regardless of the presence of symptoms, such as exercise intolerance or fatigue), were referred for catheter intervention. ${ }^{17,18}$ If no tricuspid regurgitation was detected on echocardiography, systolic flattening of the interventricular septum was considered a reliable indicator of a high ( $>50 \%$ systemic) RV systolic pressure. ${ }^{19}$

\section{Technique}

Under general anesthesia, routine right heart hemodynamics and angiography (right ventricle and main and branch pulmonary arteries) were performed before and after stent implantation. Occasionally, to profile the valve, the lateral image intensifier was positioned slightly cranial or caudal by using the radiopaque band on the bioprosthetic valve sewing ring (Figure 1) to adjust the beam. The minimal valve opening diameter was measured angiographically in the anterior cranial-caudal and lateral views, as was the length of the main pulmonary artery segment and distance from the radiopaque ring to the RV muscular cavity. The known diameter of the angiography catheter was used to correct for magnification.

The technique of stent delivery has been described in detail elsewhere. ${ }^{17,18,20}$ Palmaz stents (Johnson \& Johnson Interventional Systems, Warren, NJ) were used in all patients. In general, a complex consisting of a long sheath (Mullins type, sizes $8 \mathrm{~F}$ to $12 \mathrm{~F}$; Cook, Bloomington, Ind), a stent, and a balloon (diameters 12-23 mm, lengths 3-5.5 cm; Mansfield, Boston Scientific, Watertown, Mass) was advanced percutaneously as a single unit over an 0.035-inch extrastiff guide wire (260-cm length, Amplatz ExtraStiff, Cook) to lie across the area of stenosis within the bioprosthetic valve (usually just above the metallic valvular ring) but still within the Dacron or pericardial patch extension used for RV outflow enlargement. Stent diameters (ie, balloon diameters) were chosen to be 3 or $4 \mathrm{~mm}$ less than the rated valve diameter to allow for the thickness of the sewing ring. As such, the stent was implanted to have a slight waist (Figure 1). The length of the stent was chosen to allow the positioning across the sewing ring and complete apposition against the valve leaflets along the main pulmonary artery wall. Once the stent was expanded and in a stable 
TABLE 1. Patient data

\begin{tabular}{|c|c|c|c|c|c|c|}
\hline $\begin{array}{l}\text { Patient } \\
\text { No. }\end{array}$ & Sex & Diagnosis & Operations (age, y) & $\begin{array}{l}\text { Type and size } \\
\text { of valve }\end{array}$ & $\begin{array}{c}\text { Age at } \\
\text { catheterization } \\
\text { (y) }\end{array}$ & $\begin{array}{l}\text { Interval from } \\
\text { valve implant } \\
\text { (y) }\end{array}$ \\
\hline 1 & $\mathrm{M}$ & TOF, APVS & TOF repair + valve implant (2.7) & Mitroflow 19 & 6.5 & 3.8 \\
\hline 2 & $\mathrm{~F}$ & $\begin{array}{l}\text { TOF, APVS, PAPVD } \\
\text { to SVC }\end{array}$ & $\begin{array}{l}\text { TOF repair (monocusp valve) (0.2), resection of RVOT } \\
\text { and conduit insertion (0.4), conduit revision (1.8), } \\
\text { valve implant (2.2) }\end{array}$ & Mitroflow 19 & 6 & 3.8 \\
\hline 3 & M & $\begin{array}{l}\text { TOF, PAPVD to } \\
\text { SVC, LSVC to CS }\end{array}$ & $\begin{array}{l}\text { BTS (0.2), TOF repair (2.5), valve implant and } \\
\text { resection RVOT aneurysm (4.5) }\end{array}$ & Mitroflow 25 & 10.3 & 5.8 \\
\hline 4 & $\mathrm{~F}$ & TOF, AVSD & Total repair + valve implant $(2.5)$ & Mitroflow 19 & 7.9 & 5.4 \\
\hline 5 & M & TOF, absent LPA & $\begin{array}{l}\text { BTS }(0.1) \text {, total repair to RPA with conduit and } \\
\text { preservation of native RVOT and valve implant }(5.3)\end{array}$ & $\begin{array}{l}\text { Medtronic } \\
\text { Intact } 23\end{array}$ & 14.5 & 9.2 \\
\hline 6 & M & $\begin{array}{l}\text { Congenital PI/PS, } \\
\text { PDA, ASD }\end{array}$ & PDA ligation and valve implant (0.02) & Mitroflow 19 & 7.9 & 7.9 \\
\hline 7 & $\mathrm{~F}$ & TOF, APVS & TOF repair (0.16), valve implant (0.4) & Mitroflow 19 & 5.8 & 5.4 \\
\hline 8 & M & TOF, APVS & TOF repair and valve implant (4.4) & Mitroflow 21 & 9.7 & 5.3 \\
\hline 9 & M & TGA, VSD, PS & Rastelli repair (5.0) and valve implant (8.7) & Mitroflow 21 & 15.2 & 6.5 \\
\hline
\end{tabular}

TOF, Tetralogy of Fallot; APVS, absent pulmonary valve syndrome; PAPVD, partial anomalous pulmonary venous drainage; SVC, superior vena cava; RVOT, right ventricular outflow tract; $L S V C$, left superior vena cava; $C S$, coronary sinus; $B T S$, Blalock-Taussing shunt; $A V S D$, atrioventricular septal defect; $L P A$, left pulmonary artery; $R P A$, right pulmonary artery; $P I$, pulmonary insufficiency; $P S$, pulmonary stenosis; $P D A$, patent ductus arteriosus; $A S D$, atrial septal defect; TGA, transposition of the great arteries; VSD, ventricular septal defect.

position, no further attempts to flare the stent ends were performed. Prior balloon dilatation of the bioprosthetic valve was performed in 1 patient without any decrease in RV systolic pressure.

Cefazolin (40 mg/kg per dose; maximum, $1 \mathrm{~g}$ ) was administered intravenously at the time of catheterization and every 8 hours for a total of 3 doses. Heparin sulfate was administered in the catheterization laboratory (150 IU/kg; maximum, $5000 \mathrm{IU})$ and maintained as a continuous infusion until the following morning (10 IU $\cdot \mathrm{kg}^{-1} \cdot \mathrm{h}^{-1}$ ), with no monitoring of the activated partial thromboplastin time. At discharge, a low dose of aspirin (2-5 $\mathrm{mg} \cdot \mathrm{kg}^{-1} \cdot \mathrm{d}^{-1}$; maximum, $325 \mathrm{mg}$ ) was prescribed for 3 to 6 months.

\section{Follow-Up}

Follow-up visits were at the referring cardiologist's discretion but were generally scheduled every 6 months with echocardiographic evaluation. Repeat catheterization was undertaken if progressive conduit obstruction with indications for reintervention was suspected from the echocardiographic evaluation.

\section{Statistical Analysis}

All values are expressed as means \pm SD or median and range, as applicable. A paired Student $t$ test or a Mann-Whitney rank sum test was used to compare changes in intracardiac pressures and measurements before the procedure, immediately after, and at follow-up. Linear regression was used to evaluate the correlation between pressure gradients (right ventricle to pulmonary artery) obtained at echocardiography and catheterization. A Fisher exact test was used to compare changes in the septal motion before and after the procedure.

\section{Results}

\section{Patients}

Six male and 3 female patients underwent stent placement across a bioprosthetic valve in the pulmonary position at a mean age of $9.3 \pm 3.5$ years (range, 5.9-15.2 years; median, 7.9 years), with a mean weight of $32.0 \pm 17.1 \mathrm{~kg}$ (range, $14.5-68.2 \mathrm{~kg}$; median, $27.2 \mathrm{~kg}$ ) and a mean body surface area of $1.1 \pm 0.4 \mathrm{~m}^{2}$ (range, 0.6-1.84 $\mathrm{m}^{2}$; median, $0.98 \mathrm{~m}^{2}$ ). Seven patients had repair of tetralogy of Fallot, 1 had a Rastelli repair for complete transposition of the great arteries with a ventricular septal defect and pulmonary stenosis, and 1 patient had complete repair of congenital pulmonary stenosis and insufficiency with closure of an atrial septal defect and patent arterial duct (Table 1). In 6 patients the valve implant was in the orthotopic position. The 3 remaining patients had a bioprosthetic pulmonary valve located within a conduit, 2 having had previous operations that involved conduits (ie, 1 Rastelli procedure [patient 9] and 1 conduit placed anterior to the native RV outflow tract [patient 5]). Both of these patients had subsequent operations, with implantation of a bioprosthetic pulmonary valve within the conduit. The third patient (patient 2) had a conventional repair of tetralogy of Fallot with an RV outflow tract patch. However, because of development of an RV outflow tract aneurysm, the patient underwent resection of the aneurysm, and a conduit was placed within the native RV outflow tract, subsequently undergoing conduit revision and then a valve implant. A Mitroflow (bovine pericardial) valve (Mitroflow International, Inc, Richmond, British Columbia, Canada) was implanted in 8 patients, and a Medtronic Intact (porcine aortic) valve (Medtronic, Minneapolis, Minn) was implanted in 1 patient. The median time between the last surgical procedure and stent implantation was 7.9 years (range, 3.8-9.2 years; mean, $5.9 \pm 1.8$ years). Seven patients had exercise intolerance (with fatigue), 1 had chest pain, and 1 was asymptomatic. 
TABLE 2. Immediate results after stent implantation

\begin{tabular}{|c|c|c|c|c|}
\hline & Before & After & Change (\%) & $P$ value \\
\hline RV-PA gradient $(\mathrm{mm} \mathrm{Hg})$ & $\begin{array}{c}49.7 \pm 8.5 \\
\text { (range } 38-64 \text { ) }\end{array}$ & $\begin{array}{l}11.0 \pm 5.9 \\
\text { (range 2-20) }\end{array}$ & $-78.9 \pm 11.1$ & $\leq .001(\mathrm{n}=8)^{*}$ \\
\hline $\mathrm{RVp}(\mathrm{mm} \mathrm{Hg})$ & $\begin{array}{c}74.3 \pm 9.8 \\
\text { (range } 56-90 \text { ) }\end{array}$ & $\begin{array}{c}39.6 \pm 8.5 \\
\text { (range } 30-56 \text { ) }\end{array}$ & $-46.6 \pm 9.9$ & $\leq .001(\mathrm{n}=9)^{*}$ \\
\hline $\mathrm{Sp}(\mathrm{mm} \mathrm{Hg})$ & $\begin{array}{c}91.8 \pm 12.1 \\
\text { (range } 77-116 \text { ) }\end{array}$ & $\begin{array}{c}97.0 \pm 10.9 \\
\text { (range } 80-115 \text { ) }\end{array}$ & $6.9 \pm 15.8$ & $.275(\mathrm{n}=9)^{*}$ \\
\hline $\mathrm{RVp} / \mathrm{Sp}$ ratio & $\begin{array}{c}0.83 \pm 0.16 \\
\text { (range } 0.48-1.08 \text { ) }\end{array}$ & $\begin{array}{c}0.41 \pm 0.10 \\
\text { (range } 0.26-0.56 \text { ) }\end{array}$ & $-49.5 \pm 9.5$ & $\leq .001(\mathrm{n}=9)^{*}$ \\
\hline RVedp (mm Hg) & $\begin{array}{l}10.8 \pm 5.4 \\
\text { (range } 5-22 \text { ) }\end{array}$ & $\begin{array}{c}9.3 \pm 3.2 \\
\text { (range 6-16) }\end{array}$ & $-4.7 \pm 20.5$ & $.5(n=9)^{*}$ \\
\hline MPAp systolic (mm Hg) & $\begin{array}{c}24.7 \pm 4.2 \\
\text { (range 18-30) }\end{array}$ & $\begin{array}{c}27.2 \pm 5.0 \\
\text { (range 22-36) }\end{array}$ & $8.0 \pm 7.9$ & $.27(\mathrm{n}=8)^{*}$ \\
\hline AP diameter (mm) & $\begin{array}{l}\text { Median } 10 \\
\text { (range 5-12) }\end{array}$ & $\begin{array}{c}\text { Median } 15 \\
\text { (range 11-16) }\end{array}$ & $\begin{array}{c}\text { Median } 35.4 \\
\text { (range 25-200) }\end{array}$ & $\leq .001(\mathrm{n}=8) \dagger$ \\
\hline Lat diameter (mm) & $\begin{array}{c}\text { Median } 10 \\
\text { (range 6-13) }\end{array}$ & $\begin{array}{l}\text { Median 15.8 } \\
\text { (range 12-17) }\end{array}$ & $\begin{array}{c}\text { Median } 2.8 \\
\text { (range 20-136) }\end{array}$ & $\leq .001(\mathrm{n}=8) \dagger$ \\
\hline
\end{tabular}

$R V$, Right ventricle; $P A$, pulmonary artery; $R V p$, right ventricular pressure; $S p$, systemic arterial pressure; $R V e d p$, right ventricular end-diastolic pressure; $M P A p$, main pulmonary artery pressure; $A P$, anteroposterior; Lat, lateral.

*By $t$ test.

†By Mann-Whitney rank sum test.

On echocardiography, performed at a median of 3 months (range, 0.5-12 months) before the stent procedure, all patients had significant pulmonary regurgitation (3 moderate and 6 severe), increased RV end-diastolic dimensions corrected for body surface area (mean, 146\% $\pm 35 \%$ ), and abnormal septal motion with flattening in systole. The mean peak instantaneous gradient across the valve was $74.7 \pm$ $15.9 \mathrm{~mm} \mathrm{Hg}(\mathrm{n}=9)$. Tricuspid regurgitation was absent in 2 patients, and trivial or mild regurgitation was present in the remainder. RV systolic pressure estimate (by velocity of tricuspid regurgitation jet) was only possible in 5 patients, in whom the RV/systemic arterial pressure ratio was $0.9 \pm 0.2$. Gradients, detected by means of echocardiography (with patients awake), did not show a correlation with those obtained by means of catheterization $(r=0.1, P=.79)$. Mild systolic RV dysfunction (assessed qualitatively) was present in 3 patients.

\section{Immediate Results}

Calcification at the level of the valve leaflets was present in all implants to variable degrees. In all patients the valve appeared angiographically to be fixed in a semiopened position, with reduced mobility and variable degrees of leaflet fusion to the adjacent wall (Figure 1). There were no signs of external compression by the sternum or stenosis at the suture line between the Dacron-pericardial patch extension and the right ventricle or the main pulmonary artery. A single P4014 stent (40-mm long) was implanted in 7 patients, and a single P308 stent (30-mm long) was implanted in 2 patients. Patient 5 underwent an unsuccessful attempt at balloon dilation of the bioprosthetic valve with an 18-mmdiameter balloon before stent implantation.

The right ventricle to pulmonary artery gradient and the $\mathrm{RV} /$ systemic arterial pressure ratio decreased significantly by $78.9 \% \pm 11.1 \%$ and $49.5 \% \pm 9.5 \%$, respectively $(P \leq$ .001 for both, Table 2). No patient had a final outflow gradient of greater than $50 \mathrm{~mm} \mathrm{Hg}$ or an RV systolic pressure of greater than two thirds of the systemic arterial pressure. Angiographic diameter of the stenotic region in the frontal and lateral views increased significantly by similar increments (median, $52.8 \%$ and $35.4 \%$, respectively; $P<.001$; Table 2). Mean fluoroscopy time was $33.1 \pm 9.5$ minutes (range, 15-42 minutes). Qualitative estimate of RV systolic function improved immediately after stent implantation in all patients with previous dysfunction, as evidenced by improved RV free wall excursion. One patient had a self-limited episode of Weckenbach atrioventricular block, and in 1 patient the P4014 stent was not fully expanded after initial implantation with an 18-mm balloon and required several balloon dilatations before expanding the stent to $18 \mathrm{~mm}$. There were no significant procedural complications, and in no instance did the stents contact the RV free wall or cause obstruction to the branch pulmonary arteries. All patients were discharged home the following day. There were no complications related to vascular access.

\section{Follow-Up Results}

One patient was lost to follow-up. Mean follow-up (visits included clinical and echocardiographic examination) was $10.9 \pm 8.1$ months (range, 1-24 months; median, 12 
months). Patient 2 had a repeat catheterization 1 year after the index procedure. RV systolic pressure was $60 \%$ of the systemic arterial pressure during general anesthesia. Even though there was no localized area of stenosis within the stent (P308), it was dilated with a 12-mm-diameter balloon, and no significant increase in stent diameter or decrease in the RV/systemic pressure ratio occurred. Because it was believed that the child had outgrown the size of the valve implant, the patient subsequently underwent an uncomplicated pulmonary valve replacement with insertion of a 23-mm Hancock valve (Medtronic, Inc) at the age of 8 years (14 months after the index stent implantation procedure). The stent was cut across with heavy scissors, and the valve was removed by using conventional approaches for valve replacement.

The 7 other patients available for follow-up reported a subjective improvement in exercise tolerance and activity level after stent implantation. On echocardiography at most recent follow-up, all patients had, as anticipated, free pulmonary insufficiency, and RV end-diastolic dimensions corrected for body surface area were similar to those before implantation (mean, $143 \% \pm 37 \% ; P=.88$ ). Septal flattening in systole disappeared in all patients $(P<.001)$. The mean peak instantaneous gradient across the valve was $31.7 \pm 9.6 \mathrm{~mm} \mathrm{Hg}(\mathrm{n}=7)$, and the $\mathrm{RV} /$ systemic arterial pressure ratio, available in 5 patients, was $0.51 \pm 0.12$. No patient had more than mild tricuspid regurgitation. RV function was qualitatively mildly reduced in 1 patient and normal in the remaining 6 patients. No endarteritis occurred in the follow-up period. There were no stent fractures or embolizations during the follow-up period.

\section{Discussion}

The experimental use of balloon expandable stents to relieve obstructions within right heart valved conduits was first described by Almagor and colleagues. ${ }^{21}$ Subsequent clinical studies from this and other institutions have demonstrated the safety and efficacy of this palliative procedure, postponing the requirement for surgical conduit replacement. ${ }^{15-18,22}$ However, the role of this palliative approach to specifically relieve stenosis within a bioprosthetic valve has not been reviewed.

Differences in the mechanism of late bioprosthetic valve dysfunction and obstruction within homograft (tissuevalved) conduits might explain some of the observations in this study. Calcification and thrombosis of the commissures result in stenosis by holding the rigid cusps in a semiopened position, which is a common late finding after valve insertion. ${ }^{23}$ In addition, valve incompetence caused by thrombosis of the valve sinuses with adherence of the cusp tissue to the adjacent wall is also frequently present. ${ }^{23}$ Because of obscure reasons, calcium deposition with progressive valve degeneration is more pronounced in children than in adults, further shortening the longevity of such valves. ${ }^{4-7}$ Contrary to these observations in bioprosthetic valves, conduit obstruction appears to be due to an internal fibrous peel formation, with or without concomitant valve stenosis ${ }^{23}$ or retraction of the patch extension to the RV free wall. Because conduits are longer and located in nonanatomic positions beneath the sternum, they are also more prone to compression and kinking. ${ }^{16,18,23}$ In this series calcification and fixation of the valves in a semiopened position with reduced mobility and variable degree of fusion of the leaflets to the adjacent wall were demonstrated on angiography in all patients. The more posterior position of the valve implant similarly decreases the risk of stent fracture caused by external compression. Meticulous attention to positioning, stent deployment across the area of stenosis at the level of the leaflets but still within the Dacron or pericardial extension, and avoidance of stent contact with the heart are crucial to prevent fractures with subsequent fragment embolization. Additionally, flaring the ends of the stent was not necessary to secure the stent in a stable position.

Because stenosis within bioprosthetic valves is a more localized phenomenon, ${ }^{24}$ stent implantation optimally relieves the obstructive area, reducing the outflow gradient. As such, the immediate results were good, despite the presence of calcium deposits within the leaflets or thrombus within the sinuses. In contrast, results might not be as satisfactory in conduits affected by a diffuse calcified fibrous peeling, external compression, or kinking. ${ }^{16,18}$

This palliative procedure is not intended as a long-term solution to the problem of RV outflow tract obstruction. Its goal is to provide a reliable, safe, easily applied method to reduce RV pressure, avoiding the requirement of early reoperation. In this series 1 patient required valve replacement 14 months after the index stent procedure because the child had outgrown the size of the stent (limited by the diameter of the bioprosthetic valve implant). Accordingly, from this experience, in the absence of a discrete lesion within the stent or a newly acquired more distal obstruction, surgical replacement is recommended rather than stent redilation. ${ }^{18}$ The remaining 7 patients continue to be asymptomatic and benefit from obstruction relief with preserved RV systolic function and RV systolic pressures of less than $50 \%$ of systemic levels.

Because significant pulmonary insufficiency was already present in all patients before stent implantation, worsening of preexisting volume overload was not an issue. In this regard, RV end-diastolic dimensions have not significantly increased during follow-up, and free pulmonary insufficiency in the absence of pressure overload appears to be well tolerated. Free pulmonary insufficiency is unlikely to cause RV failure over a short period of time, particularly if the ventricle has restrictive physiologic characteristics, as is the case in many postoperative patients with tetralogy of Fallot. ${ }^{25}$ However, it might be poorly tolerated if there are 
additional residual lesions, such as distal pulmonary artery stenoses. ${ }^{26}$ Therefore accurate angiographic diagnosis and aggressive treatment of such distal lesions is mandatory at the time of stent placement.

Although no significant complications occurred in this series, compression of a coronary artery is a potential problem that might complicate the procedure, especially when the underlying anatomy is accompanied by preexisting coronary abnormalities. ${ }^{27}$ Although this palliative technique has limited application in the small infant, it might be used under special circumstances as a rescue measure. ${ }^{28}$

In conclusion, this review demonstrates the feasibility, safety, and efficacy of stent implantation across stenotic bioprosthetic valves in the pulmonary position. The localized obstruction seen at the level of the leaflets, although fixed and calcified, responds well to stent implantation, allowing postponement of reoperation with good clinical tolerance at short-term follow-up.

This study is limited by a small cohort with a relatively short follow-up period. A larger study involving longer follow-up and more objective measures of cardiovascular performance before and after intervention (ie, exercise testing) and measures of RV volumes would also aid in assessing the effect of this palliative strategy on RV function.

\section{References}

1. Razzouk AJ, Williams WG, Cleveland DC, Coles JG, Rebeyka IM, Trusler GA et al. Surgical connections from ventricle to pulmonary artery. Comparison of four types of valved implants. Circulation. 1992;86(suppl II):154-8.

2. Cleveland DC, Williams WG, Razzouk AJ, Trusler GA, Rebeyka IM, Duffy L, et al. Failure of cryopreserved homograft valved conduits in the pulmonary circulation. Circulation. 1992;86(suppl II):150-3.

3. Yemets IM, Williams WG, Webb GD, Harrison DA, McLaughlin PR, Trusler GA, et al. Pulmonary valve replacement late after repair of tetralogy of Fallot. Ann Thorac Surg. 1997;64:526-30.

4. Dunn JM. Porcine valve durability in children. Ann Thorac Surg. 1981;32:357-68.

5. Sanders SP, Levy RJ, Freed MD, Norwood WI, Castaneda AR. Use of Hancock porcine xenografts in children and adolescents. Am J Cardiol. 1980;46:429-38.

6. Silver MM, Pollock J, Silver MD, Williams WG, Trusler GA. Calcification in porcine xenograft valves in children. Am J Cardiol. 1980; 45:685-9.

7. Thandroyen FT, Whitton IN, Pirie D, Rogers MA, Mitha AS. Severe calcification of glutaraldehyde-preserved porcine xenografts in children. Am J Cardiol. 1980;45:690-6.

8. Downing TP, Danielson GK, Schaff HV, Puga FJ, Edwards WD, Driscoll DJ. Replacement of obstructed right ventricular-pulmonary arterial valved conduits with nonvalved conduits in children. Circulation. 1985;72(suppl):II84-7.

9. Waldman JD, Schoen FJ, Kirkpatrick SE, Mathewson JW, George L, Lamberti JJ. Balloon dilatation of porcine bioprosthetic valves in the pulmonary position. Circulation. 1987;76:109-14.
10. Lloyd TR, Marvin WJ Jr, Mahoney LT, Lauer RM. Balloon dilation valvuloplasty of bioprosthetic valves in extracardiac conduits. Am Heart J. 1987;114:268-74.

11. Ensing GJ, Hagler DJ, Seward JB, Julsrud PR, Mair DD. Caveats of balloon dilation of conduits and conduit valves. J Am Coll Cardiol. 1989;14:397-400.

12. Zeevi B, Keane JF, Perry SB, Lock JE. Balloon dilation of postoperative right ventricular outflow obstructions. J Am Coll Cardiol. 1989; 14:401-8.

13. Ritter SB. Balloon dilation: recession or inflation? J Am Coll Cardiol. 1989;14:409-12.

14. Keane D, Bet MM, Ross DN, Jackson G. Balloon dilatation of a bioprosthetic pulmonary valve. Int J Cardiol. 1993;38:323-5.

15. Hosking MC, Benson LN, Nakanishi T, Burrows PE, Williams WG, Freedom RM. Intravascular stent prosthesis for right ventricular outflow obstruction. J Am Coll Cardiol. 1992;20:373-80.

16. Powell AJ, Lock JE, Keane JF, Perry SB. Prolongation of RV-PA conduit life span by percutaneous stent implantation. Intermediateterm results. Circulation. 1995;92:3282-8.

17. Hayes AM, Nykanen DG, McCrindle BW, Smallhorn JF, Freedom RM, Benson LN. Use of balloon expandable stents in the palliative relief of obstructed right ventricular conduits. Cardiol Young. 1997; 7:423-33

18. Ovaert C, Caldarone CA, McCrindle BW, Nykanen D, Freedom RM, Coles JG, et al. Endovascular stent implantation for the management of postoperative right ventricular outflow tract obstruction: clinical efficacy. J Thorac Cardiovasc Surg. 1999;118:886-93.

19. King ME, Braun H, Goldblatt A, Liberthson R, Weyman AE. Interventricular septal configuration as a predictor of right ventricular systolic hypertension in children: a cross-sectional echocardiographic study. Circulation. 1983;68:68-75.

20. Benson LN, Nykanen D, Freedom RM. Endovascular stents in congenital heart disease. Prog Cardiovasc Dis. 1996;39:165-86.

21. Almagor Y, Prevosti LG, Bartorelli AL, Keren G, Ferrans VJ, Jones $\mathrm{M}$, et al. Balloon expandable stent implantation in stenotic right heart valved conduits. J Am Coll Cardiol. 1990;16:1310-4.

22. Saliba Z, Bonhoeffer P, Aggoun Y, Iserin L, Butera G, Bonnet D, et al. Treatment of obstruction of prosthetic conduct by percutaneous implantation of stents. Arch Mal Coeur Vaiss. 1999;92:591-6.

23. Agarwal KC, Edwards WD, Feldt RH, Danielson GK, Puga FJ, McGoon DC. Clinicopathological correlates of obstructed right-sided porcine-valved extracardiac conduits. J Thorac Cardiovasc Surg. 1981;81:591-601.

24. Salim MA, DiSessa TG, Alpert BS, Arheart KL, Novick WM, Watson DC Jr. The fate of homograft conduits in children with congenital heart disease: an angiographic study. Ann Thorac Surg. 1995;59:6773.

25. Gatzoulis MA, Clark AL, Cullen S, Newman CG, Redington AN. Right ventricular diastolic function 15 to 35 years after repair of tetralogy of Fallot. Restrictive physiology predicts superior exercise performance. Circulation. 1995;91:1775-81.

26. Ilbawi MN, Idriss FS, DeLeon SY, Muster AJ, Gidding SS, Berry TE, et al. Factors that exaggerate the deleterious effects of pulmonary insufficiency on the right ventricle after tetralogy repair. Surgical implications. J Thorac Cardiovasc Surg. 1987;93:36-44.

27. Maheshwari S, Bruckheimer E, Nehgme RA, Fahey JT, Kholwadwala D, Hellenbrand WE. Single coronary artery complicating stent implantation for homograft stenosis in tetralogy of Fallot. Cathet Cardiovasc Diagn. 1997;42:405-7.

28. Hatai Y, Nykanen DG, Williams WG, Freedom RM, Benson LN. Endovascular stents in children under 1 year of age: acute impact and late results. Br Heart J. 1995;74:689-95. 